\title{
Leibniz. Del dogmatismo metafísico al idealismo de la intelectualidad del universo
}

\section{Leibniz. From metaphysical dogmatism to idealism of the intellectuality of the universe}

\author{
Diana María López*
}

\begin{abstract}
Resumen: Hegel reconoce en la "idealidad" de la mónada un antecedente necesario para la comprensión lógico-ontológica del "ser para sî" (Fürsichsein) en el contexto de la superación de la oposición entre finito e infinito de la lógica del ser, a la vez que la anticipación de la formulación idealista del principio "la sustancialidad es subjetividad". A los efectos de la comprobación de esta tesis el presente artículo comienza por las nociones de "representación" e "idealismo" a partir de las cuales Kant se permite asociar la doctrina de Leibniz a un "dogmatismo metafísico", dado que Hegel presupone su conocimiento. Para pasar en un segundo momento a la crítica posición de Hegel en torno a la "idealidad" de la mónada, en la que ésta se mide con el aporte de interpretaciones que el propio idealismo alemán -transcendental, primero, y subjetivo, después- fue generando.
\end{abstract}

Palabras clave: mónada, idealidad, representación, sustancialidad, subjetividad.

Abstract: Hegel recognizes in the "ideality" of the monad a necessary antecedent for the logical-ontological understanding of "being for itself" (Fürsichsein) in the context of overcoming the opposition between finite and infinite of the logic of being, at the same time that the anticipation of the idealistic formulation of the principle "substantiality is subjectivity". For the purposes of verifying this thesis, this article begins with the notions of "representation" and "idealism" from which Kant allows himself to associate Leibniz's doctrine with a "metaphysical dogmatism", since Hegel

\footnotetext{
* Doctora en Filosofía por la Universidad del Salvador (Argentina). Se ha desempeñado como Docente e Investigadora en la Universidad Nacional del Litoral, la Universidad Nacional de Rosario y la Universidad de la República (Uruguay). Autora de numerosas publicaciones y comunicaciones sobre el Idealismo alemán, también ha sido compiladora de los siguientes volúmenes: Experiencia y límite. Kant-Kolloquium (2009), Experiencia y concepto. Hegel-Kolloquium (2011), Ser, razón y lenguaje. El problema de la universalidad y la cuestión del fundamento (2014), Ciencia, sistema e idealismo. Investigaciones y debates (2016), y El Idealismo alemán como filosofía de la libertad. Julio De Zan In Memoriam (2020). Dirección electrónica: dianalopezfilo@gmail.com
} 
presupposes their knowledge. To pass in a second moment to Hegel's critical position regarding the "ideality" of the monad, in which it is measured with the contribution of interpretations that German idealism itself -transcendental, first, and subjective, laterwas generating.

Keywords: monad, ideality, representation, substantiality, subjectivity.

En varios escritos de Hegel encontramos afirmaciones acerca de la filosofía de Leibniz, pero en ninguno de sus textos las ha expresado más sistemáticamente que en la Ciencia de la lógica ${ }^{1}$ en ocasión del tratamiento de categorías puntuales. Es precisamente en la Lógica Objetiva, la cual se divide en Doctrina del ser y Doctrina de la esencia, donde Hegel se refiere expresamente a Leibniz. Si se considera que esta referencia, especialmente en el Capítulo tercero de la Sección primera de la Doctrina del ser, bajo el título "El ser para sí" (Das Fürsichsein), es más bien marginal, entonces la intención de este artículo requiere una justificación explícita. Esta necesidad se potencia aún más si se tiene en cuenta que Hegel no se refiere solamente a Leibniz sino también a otros autores de la tradición filosófica (por ejemplo, Spinoza y Kant) a los que les dedica una mayor extensión. ${ }^{2}$

${ }^{1}$ Hegel, G.W.F., Wissenschaft der Logik. Erster Band. Die objektive Logik (1812-1813). Hrg. von Fr. Hogemann/Walter Jaeschke, Hamburg (Düsseldorf), Felix Meiner Verlag, 1978, Gesammelte Werke, Hrg. von der Rheinisch-Westfälischen Akademie der Wissenschaften, Bd. 11. Traducción española de Félix Duque, Madrid, Abada Editores, 2011. En adelante SL, para la "Doctrina del ser" (Die Lebre vom Sein) y WL para la "Doctrina de la esencia" (Die Lehre vom Wesen). Citaremos con un primer número que corresponderá a la paginación del volumen 11 de la edición académica y un segundo número, luego del punto y coma, correspondiente a la versión española. Se citará con SL1 cuando se trate de la "Doctrina del ser" correspondiente a la edición de 1832 (Die Lehre vom Sein (1832), H.-J. Gawoll/W. Jaeschke (Hrg.), Hamburg, Felix Meiner Verlag, 2008); versión española de Rodolfo Mondolfo, Buenos Aires, Solar, 1968.

${ }^{2} \mathrm{La}$ diversidad de influencias que se articulan en el pensamiento de Hegel vuelve imprescindible la búsqueda minuciosa de los episodios que han marcado hitos en su formación. Cada uno de los puntos construye el discurso en torno de un aspecto que debe ser tenido en cuenta en vistas del todo, pero que, sin embargo, resulta de tal densidad conceptual que merece ser profundizada en cada caso. Aquí, como en el resto de la obra, se pone de manifiesto uno de los rasgos más característicos del tratamiento 
En este contexto, un estudio que considere la relación Leibniz-Hegel, debería contemplar la obra en su conjunto, a la vez que todas aquellas instancias en las que el autor expresamente se refiere al filósofo de Leipzig. Sin embargo, dado los límites de este trabajo, nos centraremos en una selección de pasajes en los que Hegel se refiere a las categorías de "idealidad" (Idealität) y "representación" (Vorstellung) en relación con la noción de "mónada" (Monaden) conforme se concibe en el marco de la doctrina leibniziana. Aquí Hegel se instala históricamente en diálogo con la Monadología, ${ }^{3}$ ámbito expresivo en el que la escritura estimula la interrogación a la vez que recupera la necesidad de respuestas sobre cuestiones universales en sus articulaciones finitas.

Distinguir el camino de la posibilidad del diálogo, supone no perder de vista que los límites del proceso de discernimiento, así como los alcances del procesamiento de este proceso, son difíciles de mensurar. Sin embargo, el valor de lo que está en juego, nos insta a sostener la tesis básica de este escrito: Hegel reconoce en la "idealidad" de la mónada un antecedente necesario para la comprensión lógico-ontológica del "ser para sî" (Fürsichsein) en el contexto de la superación de la oposición entre finito e infinito de la lógica del ser, a la vez que la anticipación de la formulación idealista del principio "la sustancialidad es subjetividad", según el cual la eficacia de la razón especulativa no tiene que ver con las limitaciones del conocimiento del sujeto, sino con las posibilidades mismas de la objetividad del pensar.

A los efectos de la comprobación de esta tesis es necesario comenzar por las nociones de "representación" e "idealismo" a partir de las cuales Kant se permite asociar la doctrina de Leibniz a un "dogmatismo metafísico", dado que Hegel presupone su conocimiento. Para pasar en un segundo momento a la crítica posición de Hegel en torno a la "idealidad" de la mónada, en la que ésta se mide con el aporte de interpretaciones que el propio idealismo alemán -transcendental, primero, y subjetivo, después- fue generando.

hegeliano de los problemas lógico-metafísicos: éstos no surgen nunca "en el vacío", sino que "reformulan" y sistematizan las doctrinas de los grandes filósofos, de modo que en el ámbito del puro pensamiento se cumple la consigna hegeliana: hacer ver la necesidad del paralelismo entre el curso histórico (aquí de la historia de la metafísica) y el lógico-metafísico.

${ }^{3}$ Leibniz, G.W., Monadología, traducción española de Julián Velarde, edición trilingüe, Oviedo, Pentalfa, 1981. En adelante, Mon. 
Si la crítica sostenida por Hegel acierta con la posición defendida por Leibniz, no sólo habrá de reconocerse que ambas se contienen y expanden en un doble movimiento de com-plicatio y explicatio, sino, además, que dicha crítica ofrece una plausible interpretación del pensamiento de Leibniz, como así también, una ampliación y profundización del alcance de la fundamentación ontológica del propio sistema de Hegel.

\section{Dogmatismo y “progresos de la metafísica”.}

En 1795, el redescubrimiento potente de Leibniz y Spinoza estaba ya en manos idealistas. La elaboración de los manuscritos sobre los "progresos de la metafísica" por parte de Kant resulta absolutamente indispensable para comprender el acabamiento (a la vez final y eclosión) de esta disciplina en el contexto del movimiento llamado "idealismo alemán".

Alrededor de 1789, Kant se considera en condiciones de probar que, bien entendida, la doctrina leibniziana está en la dirección del criticismo. Sólo al final de la Respuesta a Eberbard, intentará mostrar que las tres grandes doctrinas leibnizianas: el principio de razón suficiente, la monadología y la armonía preestablecida, interpretadas desde el criticismo, y atendiendo a su espiritu y no a la letra, se avienen muy bien con la filosofía transcendental; más aún: "De este modo, bien podría ser la Crítica de la razón pura la auténtica apología del propio Leibniz contra sus seguidores, que creen reverenciarlo con palabras que no pueden honrarlo". ${ }^{4}$

Si la letra de la filosofía leibniziana había caído prácticamente en el olvido y sus principios dejaron de ser debatidos y defendidos, ello se debió a que habían logrado convertirse en el modo dominante del pensar; y aunque la metafísica no progresó por ello, sí se lograron importantes avances en las demás ciencias. La metafísica se convirtió en un agregado de sentencias del sentido común y proposiciones de la psicología y de la historia de la filosofía. En este contexto, la Crítica de la razón pura ${ }^{5}$ no hará otra cosa que restaurar y

\footnotetext{
${ }^{4}$ Kant, I., Por qué no es inútil una nueva crítica de la razón pura. Respuesta a Eberhard, trad. de A. Castaño Piñán, Buenos Aires, Aguilar, 1981, pp. 121, 122.

${ }^{5}$ Kant, I., Kritik der reinen Vernunf. Kant's gesammelte Schriften. Hrsg. von der Königlich Preussichen Akademie der Wissenschaften, Berlin und Leipzig, Walter der Gruyter, desde 1902. Crítica de la razón pura, traducción española de Mario Caimi, Buenos Aires,
} 
afirmar el verdadero espiritu de Leibniz, constituyéndose en el mejor bastión contra los escépticos (algo afirmado constantemente por Kant) y el establecimiento de "una nueva manera de entender" las doctrinas leibnizianas: solución del problema de la existencia de Dios y de la inmortalidad del alma, doctrina de la sustancia como algo basado en la fuerza intelectual (intellektuellen Kraft), deducción de las categorías de cantidad a partir de esta fuerza, con lo que se consigue la conexión de física y matemática, y la derivación de la metafísica hacia la moral, ambas defendidas por Leibniz. Mas no hay sólo coincidencia, sino progreso: gracias a Kant es posible comprender mejor los esfuerzos de Leibniz por compaginar harmonia praestabilita e influxus physicus, la aplicación de los conceptos (fundados en la fuerza intelectual) a los objetos gracias a la referencia de aquéllos a las sensaciones y la analogía del alma con el mundo entendido como ser vivo.

Ahora bien, que un fenómeno debe tener un fundamento último que no sea fenómeno; que de la definición de ese fundamento puedan deducirse diferentes verdades, y verdades eternas; y que no se tenga idea de esa materia simplísima, pero se puedan demostrar muchas de sus determinaciones generales, son algunas de las tesis de Leibniz que críticos del kantismo consideran que Kant ha retomado y hecho suyas sin provocar en este contexto, grandes "progresos de la metafísica". La respuesta de Kant ha sido contundente: el problema de la posibilidad interna de la metafísica implica la pregunta acerca de la posibilidad de la metaphysica generalis, de la "generalidad" con que hasta ahora se ha tratado al ens commune y de las condiciones finitas del conocimiento a priori. Si realismo e idealismo son confrontados en el ámbito teórico, es decir, en relación al origen y fundamentación de la ontología, la crítica de la razón puede considerarse como un intento de solución del problema de la representación a la hora de comprender el límite sin caer en el dogmatismo que cree poder asegurar la ampliación del conocimiento

Colihue, 2007. Se citará con la sigla $K r V$, seguida de A y B, primera y segunda edición, respectivamente.

${ }^{6}$ Los considerados dogmáticos deben ser teólogos y moralistas que, "en la infancia de la filosofía" (im Kindesalter der Philosophie) (KrV A 852, B 880) empezaron por donde Kant querría acabar: por el conocimiento de Dios y de la vida futura. Para la noción de "dogmatismo de la metafísica", ver: Caimi, M. y otros, Diccionario de la filosofía crítica kantiana, Buenos Aires, Colihue, 2017, p. 151. 
basándose en la validez objetiva del concepto de razón suficiente: “(...) dado que Leibniz, dice Kant, no creía pertinente situar a la base de éste ninguna intuición a priori, sino que reconducía la representación del mismo a meros conceptos a priori (...) tuvo como consecuencia que todas las cosas, consideradas metafísicamente fueran [vistas como] compuestas de realidad y negación, del ser y del no ser". ${ }^{7}$

Para poder mostrar la génesis de la razón que se pone límites a sí misma y ofrecer para el conocimiento de lo trascendente, "el seguro camino de la ciencia" (KrV B XVIII), Kant convierte el gran espejo de la metafísica en el campo de convergencia de aporías que llegan indirectamente a mostrar otro espacio de pensamiento, de tal modo que, la sistematización objetivotrascendental del conocimiento da paso a una apropiación subjetivotrascendental del pensar.

\section{Kant. Mónada, idealismo y representación}

En principio, lo que en Kant constituye una teoría de la "apariencia" (Schein) es la "dialéctica", ella nos explica cómo determinadas representaciones acompañan inevitablemente el discurso válido sin ser nunca ellas mismas discurso válido. Así, pues, por lo mismo que se busca no caer en antinomias, se tiende también a suprimir la pluralidad de principios en orden a uno único, incondicionado y absolutamente primero. Sin embargo, esta exigencia de una génesis del pensar determinante representa el límite de una paradoja, según la cual, la validez no puede ser un Faktum que se hace efectivo sobre la base del supuesto de una realidad metafísicamente anterior a toda reflexión. Y no puede serlo, precisamente, porque la crítica está vinculada a un sujeto ("finito") no ontológicamente mediado. No es una casualidad que Kant, en el párrafo de la "Transición a la deducción transcendental de las categorías" (KrV A 925, B 124s.) haga una alusión a la finitud de nuestra representación. El conocimiento no es ónticamente creador. Siendo "finito", ha de ser una intuición receptiva que sólo se realiza en la facultad ob-jetivante y que, en cuanto tal, no puede representarse la totalidad del ente en el sentido del totum simul, intuido por el intuitus originarius. De allí que, en el contexto de la Crítica, la representación de unidad en su calidad de pensar puro asumirá necesariamente el carácter del "Yo

\footnotetext{
${ }^{7}$ Kant, I., Los progresos de la metafísica desde Leibnizy Wolff, traducción de Félix Duque, Madrid, Tecnos, 2002, p. 50. En adelante Progr.
} 
pienso": unidad que siendo no-óntica llevará en sí la tendencia esencial a la unificación de lo que aún no está unido. ${ }^{8}$

De este modo, la polémica desatada por Wolff en torno al problema del método, revertirá en el gran interrogante kantiano acerca de la cientificidad de la metafísica y lo conducirá a identificar la "idealidad" con la forma de la representación: “( ...) el idealismo - dice-consiste en la afirmación de que sólo hay seres pensantes y las otras cosas que creemos percibir en la intuición serían solamente representaciones en los seres pensantes". ${ }^{10} \mathrm{La}$ exposición de la complejidad interna del problema de esta forma de la representación en el marco de los límites de la Crítica, habrá de distanciarlo de quienes, como Leibniz, dan otra respuesta a la formación originaria de la unidad esencial del conocimiento ontológico y al problema central de la fundamentación de la metafísica.

Para Leibniz, no hay en el mundo más que seres capaces de representaciones y sus representaciones. La única manifestación de la fuerza de las cosas en sí es pues la representación. Por eso se define a la sustancia finita como "fuerza representadora". Es decir, "mónadas". Dice Leibniz: "La mónada (...) no es otra cosa que una sustancia simple, que forma parte de los compuestos; simple, es decir, sin partes" (Mon. 1). Esta palabra no significa en sí misma más que unidad, designando en consecuencia los distintos seres sustanciales: "(...) cuyos cambios naturales vienen de un principio interno, puesto que una causa externa no puede influir en su interior" (Mon. 11). ${ }^{11}$ En este

\footnotetext{
8 Para la distinción entre "lo trascendental" y "lo especulativo", se sugiere ver Goddard, J.-Ch. (ed.), Le transcendental et le spéculatif dans l'idéalisme allemand, Paris, Vrin, 1999.

${ }_{9}$ Es bien sabido que Kant se proponía elaborar su sistema tras la propedéutica crítica, siguiendo "el método estricto del célebre Wolff” ( $r r V$ B XXXVI).

${ }^{10}$ Kant, I., Prolegomena zu einer jeden künftigen Metaphysik, die als Wissenschaft wird auftreten können. Prolegómenos a toma metafísica futura que haya de poder presentarse como ciencia, traducción de Mario Caimi, edición bilingüe, Madrid, Ágora de Ideas/Istmo, 1999, p. 99. En adelante Prol.

${ }^{11}$ Cfr. Leibniz, G.W., "Aus dem Briefwechsel zwischen Leibniz und Arnauld”, in Hauptschriften zur Grundlegung der Philosophie, Bd. 2, hrg. von A. Buchenau, Hamburg, Meiner, 1966, donde, según Leibniz, el concepto de mónada debe interpretarse por su analogía con el de alma y cuyo "modelo" a partir del cual estableció el estatuto de la mónada, fue el de la simplicidad autorreflexiva del "yo". Dice: "También es por el conocimiento de las verdades necesarias y por sus abstracciones por lo que somos elevados a los actos reflexivos, que nos hacen pensar en el llamado Yo" (Mon., \30).
} 
contexto, la representación (Vorstellung) se define como la contención de lo exterior en el interior, muchos en uno (repraesentatio multitudinis in unitate): la esencia representativa, sin perjuicio de su unidad, conlleva una multiplicidad de relaciones, el mundo entero. Cada individuo contiene un infinito en sí mismo (substantia infinitas actiones simul exercet), y una inteligencia para la cual cada representación: “(...) expresa, aunque confusamente, todo lo que sucede en el universo, pasado, presente o futuro, lo cual guarda cierta semejanza con una percepción o conocimiento infinito". ${ }^{12}$ Así, cada mónada es un espejo del universo ${ }^{13}$ que crea las imágenes de las cosas a través de su propia actividad, a la vez que una forma de existencia a cuyo concepto o esencia pertenece todo cuanto pueda predicarse de ella en cualquier momento, siéndole esenciales sus propiedades y afecciones. ${ }^{14}$ Cuanto pueda ocurrirle está determinado invariablemente de antemano por su propia naturaleza: "El alma es un mundo pequeño donde las ideas distintas son una representación de Dios y las confusas una representación del universo"(NE, 117).

Para Kant, la finitud de nuestro pensar puro respecto a lo múltiple dado en la sensibilidad "exige" que este múltiple se adapte al pensamiento mismo, es decir, al pensamiento que es determinante por medio de conceptos. La distinción de Kant entre intuición y concepto no es gradual, sino de principio, y sólo salvable mediante el esquematismo. Según Leibniz, la intuición no sensible es la representación: el objeto más simple del sentido interno y la materia más simple del tiempo inmanente: “(...) me gustaría conocer cómo podríamos tener la idea de ser, siendo seres nosotros mismos, sin encontrar el

${ }^{12}$ Leibniz, G.W., Discurso de Metafísica, traducción de A. Castaño Piñán, Buenos Aires, Aguilar, 1984, p. 74.

${ }^{13}$ En realidad, la mónada espejea los espejos: ¿dónde está la cosa que se espejea en ella? La esencia de la mónada está relacionada con las otras que en sí mismas son puntos de relación (Bezieungspunke). Por sí misma la mónada desarrolla sus representaciones. Pero la concordancia de las diferentes imágenes del mundo (Weltbilder) tiene su razón, su fundamento (Grund) en un acto divino en virtud del cual las naturalezas de las mónadas se han adecuado entre sí desde el principio (prästabilierten Harmonie), de tal modo que los cambios de sus estados, aunque se de en cada una de ellas de manera diferente, inmanente y sin acción externa, corre en paralelo y el efecto es el mismo que si tuviera lugar una influencia mutua constante.

${ }_{14}$ Cfr. Leibniz, G.W., Nuevos ensayos sobre el entendimiento bumano, traducción de J. Echeverría, Madrid, Editora Nacional, 1983, p. 80. En adelante NE. 
ser en nosotros" (NE, 88). Éste es el único carácter por el que el mundo como representación se distingue de los sueños: la regularidad de la asociación y coordinación de nuestras representaciones, y el hecho de que no se aparten de nuestras previsiones cuando éstas han sido calculadas conforme a la "necesidad":

La apercepción de cuanto está en nosotros depende de una atención y un orden (...) la atención está regida por la necesidad (...) la Naturaleza no se ha esforzado en imprimirnos los conocimientos innatos inútilmente, puesto que sin ellos no habría ningún medio de llegar al conocimiento actual de las verdades necesarias en las ciencias demostrativas, ni a la causa de los hechos; y no poseeríamos nada superior a las bestias (NE, 89).

Verdades necesarias", fenómeno regulado y enlazado sólo en la mente ("mentale quiddam") que llevará a Kant a considerar que en el "idealismo" de Leibniz se juega una existencia "mental", o como también podría decirse, meramente "conceptual", "ideal", de lo real; por lo cual: “(...) esta filosofía sigue estando, sin saberlo, en el campo de la lógica, sin haber conseguido dar un paso hacia la metafísica y menos aún dentro de ella (Prog., 42).

$\mathrm{Si}$ "saber" es tener por verdadero, a partir de un fundamento cognoscitivo suficiente, la certeza racional que se diferencia de la empírica por la conciencia de la necesidad que va unida a ella, la interconexión de las proposiciones no procede del nexo causal real entre las cosas, sino de la relación de fundamentación y demostración entre unas proposiciones y otras. Como todo aprehender la cosa toma la forma de la representación, provoca la aparición del concepto en la conciencia la apariencia de ser él mismo ya la cosa. Tal "falacia" es, para Kant, la subrepción consistente en tomar "(...) la necesidad subjetiva de una cierta conexión entre nuestros conceptos, en favor del entendimiento, por una necesidad objetiva de determinación de las cosas en sí mismas" (KrV A 297, B 353).

El resultado es la apariencia transcendental, ilusoria e inevitable, producto de una interpretación unilateral fundada en un análisis incompleto del fenómeno del conocimiento y una posición filosófica "dogmática" por su confianza ciega en la capacidad de la razón de extenderse a priori sin crítica, mediante conceptos. Dice Kant: 
(...) él [Leibniz] veía en las representaciones sensibles, como fenómenos, no un tipo de representación totalmente diferente de todos los conceptos, o sea intuición -como debe ser- sino un conocimiento, aunque confuso, por conceptos que tienen su sede en el entendimiento y no en la sensibilidad (Progr., 52)

Sin embargo, podríamos decir que, la experiencia de la "idealidad" del ser ideal propia de la mónada, resiste perfectamente la comparación con la del ser real y es incluso superior a ésta en la validez universal de su contenido. Su necesidad, lejos de estar sostenida meramente en una certeza basada en "simples conceptos", lo hace en una aprioridad trascendente, por lo cual la orientación a la ratio tiene una primacía anticipada también en lo que se refiere al fundamento. Las diversas representaciones o los diversos estados representativos de una mónada están implícitos en su ser, como los predicados están lógicamente contenidos en un sujeto o como en la naturaleza del círculo se encuentran todas las propiedades que se pueden deducir de él. La posibilidad de comprender, de convencer y convencerse, no descansa exclusivamente en la necesidad del pensamiento, sino en la identidad del objeto ideal para toda mirada dirigida a él. Dice Leibniz: "Soy de la opinión de que basta la reflexión para encontrar la idea de sustancia en nosotros mismos, que somos sustancias" (NE, 111,112). En este sentido, a diferencia de Kant para quien al fenómeno corresponde algo no fenoménico, pero no tengo concepto de ello; para Leibniz, puedo definir claramente ese concepto y deducir de él (por el principio de contradicción) predicados relativos a partes esenciales (essentialia), y derivar de él (por el principio de razón) predicados relativos a atributos de la cosa: el orden racional corresponde al orden real. Lo que la razón ve en las verdades de razón debe suceder también en el orden de los hechos. Aquí está, pues, la verdadera razón suficiente del ser de los objetos ideales:

La rąón es la verdad conocida cuya relación con otra menos conocida nos permite asentir a la última. Pero de forma particular, la razón por excelencia exige que no sólo sea la causa de nuestro juicio, sino también de la verdad misma, a lo cual se lo denomina también razón a priori, y la causa en las cosas corresponde a la razón en las verdades (NE, 579, 580).

La circunstancia de que la conciencia tenga, aquí, un acceso directo al objeto ha conducido a la concepción de que se trata meramente de algo pensado. 
Cuando, en realidad, lo que en la representación es visible con evidencia "clara" y "distinta", se ve con total independencia de todo darse o no darse los casos reales. Partiendo de los sistemas ideales y de las ordenaciones funcionales de la matemática quiere Leibniz comprender la unidad del universo que se sobrepone a la pluralidad de las sustancias individuales. También en este caso resuelve el racionalismo las relaciones causales en meras conexiones ordinales. Cada sustancia individual hállase por su esencia íntima, desde un principio y para siempre, en las relaciones sintéticas de la legalidad objetiva del universo. En este sentido, si se quisiera arrancar al ensamblado de lo real el ser de lo universal y esencial, se atentaría contra la unidad del mundo en la que se halla firmemente ligado lo heterogéneo por la interna dependencia de esa estructura ideal de relaciones esenciales.

El ser en sí de lo ideal no significa una "abstracción", un flotar ónticamente la esfera de lo ideal en un "más allá", en el trasmundo de una región independiente y separada de la realidad y de la mente, sino la determinación necesaria para que "haya" algo así como "realidad" o como "mente". La "idealidad" del representar significa, de este modo, un poner desde sí mismo algo delante y garantizar lo puesto como tal. Este garantizar tiene que ser un calcular, porque solo la calculabilidad garantiza de antemano y constantemente que se tenga la certidumbre de lo que se quiere representar. Representar es una objetivación que procede. Su certidumbre fundamental es el me cogitare =me esse. Es la ecuación fundamental de todo calcular del representar seguro de sí mismo. Es coagitatio. Algo "activo", "productivo". "Por eso, dice Leibniz, en ocasiones se llama razón a la causa misma, y en particular a la causa final" (NE, 580).

Este desequilibrio en favor de la actividad productiva y en detrimento de los meros hechos de conciencia marca decisivamente la senda por la que se moverá el idealismo alemán posterior, el cual dará un paso en dirección a la profundización y ampliación del significado teórico y práctico de "idealismo". ${ }^{15}$

15 Para la noción de “idealismo”, ver: Di Sanza, S. y López, D. M. (comps.), El vuelo del búho. Estudios sobre filosofía del idealismo, Buenos Aires, Prometeo, 2013; Lerussi, N. y Solé, M. J. (eds.), En busca del idealismo. Las transformaciones de un concepto, Buenos Aires, RAJGIF Ediciones, 2016; López, D. M. y Gaudio, M. (comps.), V ariaciones sobre temas del idealismo, Buenos Aires, RAJGIF, 2018. La definición de idealismo puede 


\section{Hegel. Mónada, idealidad e infinitud}

El camino del pensar presupone la racionalidad del pensamiento como el espacio de la realidad. A su vez, esto implica pensar la realidad como haciéndose presente en la racionalidad del pensamiento. Su trazado transcurre en un círculo que regresa a su inicio y sólo lo alcanza al final. Lo cual se puede reconocer en la concepción leibniziana de la "mónada" como "percepción percipiente" (perception perceptive) y en la noción hegeliana del "concepto concipiente" (begreiffen Begriff).

Ambos, Leibniz y Hegel, piensan su pensamiento. En ambos, el pensamiento se delimita en su racionalidad, fijando así sus propias posibilidades: replegándose sobre sí mismo, reflexiona en un espacio circular donde prima la coherencia totalizante. Para ambos, las dificultades son fundamentales en la medida que explicitan la resistencia del pensamiento al sistema, la fisura rebelde que se instala continuamente entre las cosas y la teoría, el margen de desequilibrio entre el pensar como acción concreta y el saber como representación acabada de la totalidad posible de ese pensar. ${ }^{16}$ De tal modo que, "mónada" y "concepto" pueden entenderse en clave de "logicidad en automovimiento", saber que se desprende de su relación con los objetos, génesis absoluta del ser cuya manifestación en su infinita referencia a sí, expresa la totalidad en cada uno de sus momentos.

Sin embargo, las dificultades que resultan del análisis explican el proceso de "discernimiento" llevado adelante por Hegel en el contexto del tratamiento del "ser para sî" (Fürsichsein) donde el pensamiento de Leibniz es sometido a la crítica y considerado en su "idealidad".

\subsection{Lo representado como una presuposición que está siendo}

En la nota 2 al punto sobre "El traspaso" (Der Übergang) del segundo capítulo de la Doctrina del ser (segunda edición de la Ciencia de la lógica, 1831), Hegel dice: "Cada filosofía es esencialmente un idealismo, o por lo menos lo tiene como su principio, y el problema entonces consiste sólo [en reconocer] en qué

encontrarse también en Caimi, M. y otros, Diccionario de la filosofía crítica Kantiana, pp. 244,245 y 246.

16 Cfr. Longuenesse, B., Hegel's Critique of Metaphysics, Nueva York, Cambridge University Press, 2009. 
medida ese principio se halla efectivamente realizado" (SL1, 197). Según Hegel, este "principio se halla efectivamente realizado" en la filosofía de Leibniz en tanto y en cuanto lo ideal es aquí lo finito tal como está en lo infinito verdadero. Si bien se tiende a identificar a la realidad con lo finito y a lo ideal con lo infinito, en una oposición que unilateralmente sostiene a los opuestos en una abstracción irreconciliable, en el marco de la doctrina leibniziana la mediación de la sustancialidad individual finita de la mónada tiene aquí su explicación en una noción de temporalidad sólo concebible desde el punto de vista de la infinitud.

Desde este punto de vista, el de Dios, todo lo finito se encuentra mediado a través de la condición operante de la "armonía preestablecida", de tal modo que la conciencia traspasa sus propios límites alcanzando su mayor transparencia en la unidad que se sabe a sí misma por obra de la analogía con lo divino. Si se abandona esta mediación con lo infinito y la teología racional se muestra infructuosa, entonces sólo permanece de pie la consideración de la unidad monádica de la conciencia en su finitud. Dios es en nosotros la permanencia intrínseca de la unidad absoluta, constituyéndose, de este modo, en la "ultima ratio" de una concepción de la finitud en la que yace la evidencia de la monadología: la fundación originaria de la individualidad a través del punto de vista de la conciencia y la "repraesentatio mund?" a través de la conexión universal de todo lo finito.

Independientemente de su metafísica "ausencia de ventanas" (Fernsterlosigkeit), las mónadas son "representando". Por su parte, lo representado, el contenido de cada una, tiene el modo de ser de lo que "aparece" y las realidades sustanciales en este modo del aparecer en su conjunto, conforman lo que se llama el "mundo material" (materialle Welt), racionalmente ordenado, sustancialmente inteligible y mutuamente representando por las mónadas en sus percepciones. En este sentido, dado que el conocimiento resulta del propio autodesarrollo inmanente o "fuerza originalmente activa" (ursprünglich tätigenkraft), la armonía está "preestablecida" para todos los estadios de la evolución de la mónada, sin menoscabo de la plena autarquía de su interna espontaneidad. Desde un principio y para siempre, en las relaciones sintéticas de la legalidad objetiva del universo, cada sustancia individual refleja el todo infinito como "puesto en la existencia" (Cfr. Mon., \$ 47) 
De este modo, la metafísica leibniziana, que se entiende a sí misma como una deficiente ejecución posterior de la razón originalmente perfecta en Dios, concibe toda reflexión como condicionada por un presupuesto del cual depende: la razón divina en la que todos los contenidos son igualmente originales en su orden lógico. Límite de la unificación entre lo inteligible y lo sensible, totalidad concreta de mediación de lo infinito en lo finito, lo absoluto es concebido como razón pensante, principio general de inteligibilidad y de explicación del dinamismo que se ofrece en el orden de lo existente. ${ }^{17}$ Dios, principio de las esencias que fundan las verdades necesarias y de las existencias en que se realizan las verdades contingentes, es "mónada de las mónadas", garantía de la armoniosa disposición de perfecciones desiguales pero en cohesión dentro de la unidad: “(...) sólo en sí, dice Hegel, o sea dentro de Dios como mónada de las mónadas, o también dentro del sistema, son las mónadas algo representador" (SL, 90; 272).

La creación revela así, una analogía estructural: lo que se entiende $a$ posteriori en la conciencia finita, no deja por esto de estar "en sî" (an sich) de acuerdo con la racionalidad que existe a lo largo de la creación (como originario rerum radicalis). El hecho de que todo lo creado, es decir, ontológicamente finito, pueda ser considerado como "ideal" se debe al razonamiento especulativo que se reconoce, estrictamente hablando, en el sentido de la proposición universal: "la diversidad es mismidad", donde pertenece en propiedad al "es", la significación "tiene la esencia en", precisamente porque en correspondencia con el concepto rector del ser en general, la esencia está predeterminada de manera especulativa, onto-teológicamente. Esto se pone de manifiesto en que, si bien el fenómeno de la totalidad de lo creado y lo eternamente posible dentro de la conciencia finita representadora adquiere en cada mónada una forma propia irreductible, el contenido intrínsecamente inteligible es el mismo en todas partes desde el origen.

En este contexto, la multiplicidad de las mónadas no debe interpretarse como "desintegración" de la unidad sino como resultado eo ipso del orden lógico de todos los contenidos concebidos: cada mónada existente (e incluso, cada una sólo posible) es un concepto autónomo, lógico y de máxima consistencia. Lo que da lugar a que, según Hegel, “(...) esta totalidad simple se

${ }^{17}$ Leibniz habla de una realis ratio, que identifica con la causa. No se distingue entre causa y razón. El orden lógico (razón) coincide con el orden real. 
parta en la muchedumbre absoluta de los distintos, de tal manera que éstos son mónadas autosuficientes" (En₹, \194). Pero, al mismo tiempo, a que “(...) en la armonía preestablecida de sus desarrollos internos, estas sustancias son de nuevo reducidas a su vez a falta de autosuficiencia e idealidad" (Idem.). La mediación que sólo les sucede a ellas es tal, por un fundamento que las precede: el acto divino absoluto de la razón que mantiene a todos los conceptos "en armonía", incluidas todas sus interrelaciones en la existencia. Esta verdadera "razón final" de la cual se desprende la "idealidad" ontológica que caracteriza a todo el sistema, es interpretada por Hegel, como una "alteridad" que está fuera al modo de un "límite". Así dice: "Esta limitación de la mónada acaece necesariamente, no dentro de la mónada ponente de si misma, o representadora, sino dentro de su ser en sí, o sea, es límite absoluto" (WL, 378; 602).

Habría, entonces, una unidad -la del universo- que integra la multiplicidad de las mónadas, pero también otra unidad de lo múltiple: la que caracteriza a la vida interior de cada una de ellas.

\subsection{La apertura hacia el mundo interior y la certeza de ser todo}

Hegel concluye el comentario final del $\ 194$ de la Enciclopedia, diciendo: "La filosofía leibniziana es de este modo la contradicción enteramente desarrollada". Esta contradicción consiste en que: “(...) la autonomía de las mónadas no sería tal si se considera la recíproca relación que mantienen con un fundamento común del cual dependen en él y por él”. Pero, además, en que si bien “(...) la mónada es para sí el mundo entero, aisladamente clauso" (SL, 95; 278), “(...) desarrolla a partir de sí misma sus representaciones" (WL, 247; 444). De tal modo que, en el avanzar paso a paso de la conciencia, se despliega en sí misma su propio saber: "Lo que es innato, dice Leibniz, no por esto es conocido con claridad y distinción desde el primer momento; existen grados en la dificultad que tenemos para apercibirnos de lo que hay en nosotros mismos" (NE, 79). Dado que cada mónada es un centro subjetivo cuya actividad es la de "representar" y que no refleja imágenes que vienen de afuera, sino que brotan de su propio fondo, "lo real" es lo que se configura en objetivo para la conciencia, único ámbito en el cual el carácter del aparecer es el representar en el sentido de hacer presente lo que se conoce. El on es ahora el ens qua ensperceptum y aperceptum. Dice Leibniz: “(...) lo que se llama luz natural supone un conocimiento distinto, y muy frecuentemente la consideración de la naturaleza 
de las cosas no es más que el conocimiento de nuestro espíritu y de esas ideas innatas que no hay necesidad de buscar fuera" (NE, 86, 87).

De este modo, en la interioridad de la mónada se pone de manifiesto que la unidad no es tal unidad, sino la extrema disonancia. En tanto representadora, la mónada descubre que su experiencia signada por la finitud es la del sustraerse-remitiendo-a-lo-otro. La conciencia que entiende se escinde, se hace dos: al retornar hacia sí, el núcleo no es la unidad anterior a las diferencias sino la unidad de las diferencias. La diferencia entre el representar y lo representado destruye la "simplicidad", a la vez que instala en el interior mismo de la sustancia el diferenciar como unidad de lo diferenciado. Al decir "representación", se pone el acento en su "ser para la conciencia". El énfasis en el prefijo "re" indica el respecto subjetivo. La conciencia pura no se presenta ya como identidad absoluta, sino que en su dignidad suprema está contrapuesta a la conciencia empírica. La "ausencia de ventanas" de la mónada se traduce, así, en la cancelación de la diferencia fenoménica - puesta de manifiesto en la desvalorización de la certeza sensible como fuente de conocimiento válido. Esto implica instaurar como condición de inteligibilidad la diferencia absoluta en lo inteligible mismo: ya no es lo universal que niega llevando hacia una quietud infinita y abstracta sino hacia una plenitud de mediación de lo infinito y lo finito.

Esta mediación que se consuma en los límites abiertos en la interioridad de la mónada pone de manifiesto la transfiguración de lo finito en lo infinito porque entiende que no está en juego aquí un "progreso" hacia otro exterior en sí- sino un "pasar a otro" en el que toda alteridad queda contenida y superada de tal modo que este tránsito asume la forma de un "coincidir consigo". Se trata de la simplicidad de lo múltiple. Dado que la actividad interior del representar se configura como diferencia dentro de la unidad y como posibilidad de superación de determinaciones indiferentes, esta diferencia, según Hegel, se consuma como para sí (Für sich). Así dice:

El ser para sí es la simple igualdad consigo. Tiene dentro de sí a los dos momentos diferentes, porque la simple igualdad consigo no es lo inmediato, el ser, sino que sólo es como asunción del ser otro (...) este asumir al ser otro es inmediatamente unidad que se refiere a sí (...) la esencia leibniziana es representadora $(\ldots)$ es un ser para sí $(S L, 88,89 ; 271)$. 
Si lo propio de la mónada es representar y el representar es un ser para sí en el sentido de la simple igualdad consigo de dos momentos diferentes e inseparables, este superar lo que se le opone en el ámbito de la propia inmanencia, la configura como inmediata unidad que se refiere a sí. Ahora bien, el relacionarse consigo mismo es, precisamente, la estructura de la vida. Lo viviente no es un mero caso de una ley o resultado de las leyes que recíprocamente interactúan, sino que es algo que se vuelve sobre sí. Es un sí mismo. "Sí mismo" significa autoidentidad en la indiferenciación y autodiferenciación. El modo de ser de lo viviente corresponde, en este aspecto, al modo de ser del saber mismo que entiende o comprende lo viviente desde dentro y en tanto que sí mismo. Incesante distinción de sí con respecto a sí mismo. Richard Falckenberg, dice: “Así cada mónada es un espejo del universo, pero uno vivo (miroir vivant de l'univers), que genera las imágenes de las cosas a través de su actividad sin experimentar ninguna influencia externa". ${ }^{18}$

La transposición del logos al terreno del ego, la cogitatio, el yo, producida por Descartes, ${ }^{19}$ abre el camino para la reestructuración respecto al contenido que encontrará su cauce en la monadología de Leibniz como teoría radical de la sustancialidad de la sustancia. El cumplimiento de la conciencia considerado como "formal", como mero ascenso a lo universal y abstracto, sede su paso a un dinamismo interior que implica sustituir todo objeto inmutable por el circuito de la vida en su movimiento creador: el aparecer de lo que aparece para la mónada no es sólo lo-que-se-muestra, sino que mostrarse es emerger, ponerse al descubierto del "mundo" en su saber-se.

A partir de aquí, la percepción pierde su carácter operatorio, aunque conserva su significación especulativa merced a la necesidad de la flexión (apperceptio) que pone a la conciencia en tránsito hacia un más allá de su funcionalidad. Como certidumbre, la verdad es ahora el representar mismo que

${ }^{18}$ Falckenberg, Richard, Geschichte der neueren Philosophie, Leipzig, Verlag von Veit \& Comp., 1908, p. 247. Traducción nuestra. Cfr. Mon., \ 63.

${ }^{19}$ Según Descartes, todo cogitare es un cogitare me cogitare, donde cogitare alude a un acto de la conciencia. Toda conciencia de un objeto es, al mismo tiempo, conciencia de la conciencia del objeto y, por lo tanto, autoconciencia. Tal que, "Yo pienso" no es una entidad per se sino la fijación referencial del devenir lógico del sujeto. En este sentido, en la historia de la filosofía que va de Descartes a Kant, justamente no dejó de perfilarse cada vez de una manera más clara y significativa que toda perceptio es, al mismo tiempo, apperceptio. 
se ha asegurado de su saber y con ello se ha retirado ya de todo representar objetos. Esta emancipación de la relación con los objetos implica que la conciencia abandona, en cierto modo, el representar de lo existente y, por lo tanto, ha pasado de lo aparente - de lo que aparece- al aparecer. Con lo cual se ha invertido. Lo que en esta inversión se expone a la conciencia no es "para la conciencia", es decir, no lo es para la conciencia "natural" -la cual aún no es enteramente consciente de su propia esencia. Lo que se opera aquí es la conversión de la conciencia en conciencia de sí misma. Mirar al interior es cosa del entendimiento y no ya de la percepción sensible. ${ }^{20}$ A través de la representación, la mónada descubre en el interior de sí misma el mundo real consistente en subsistir siendo constantemente otro: la apariencia en cuanto apariencia. No es, por tanto, la apariencia como opuesta a la realidad, sino más bien, lo representado en la representación como la realidad misma: el mundo.

En este sentido, es importante destacar que la realidad del mundo no solamente no es ajena a la mónada, sino que, necesariamente, se tiene que dar en ella. La necesidad no es del "mundo" -como si este fuera algo ajeno y trascendente a la pluralidad monádica- sino de cada mónada; la necesidad sólo existe "reflejada" en las distintas series en que ellas consisten. Pero, al ser esa necesidad percibida como reflexión en si (in sich) de aquello que la mónada es en cada caso, ésta "toma a su cargo" esa presunta necesidad exterior como la esencia que la constituye. Sin embargo, al contrario del fundamento, esa esencia está absolutamente diseminada en las "existencias" a las que "deja ser". El mundo existe únicamente en su manifestación fenoménica al igual que el género sólo existe en sus momentos en las cosas específicamente existentes. Y es real en la medida en que se refleja en el interior de la mónada apareciendo, haciéndose presente, en el representar de cada individuo en el referirse a sí mismo. Pero entonces, esa unidad que di-fiere infinitamente de sí, que "es" sólo cuando deja "de ser", ya no es ni "alma" ni "mundo", sino la compenetración de esos

${ }^{20}$ Lo que Hegel llamará "lo verdadero interior". Hegel, G.W.F., Phänomenologie des Geistes, Hrg. Hans-Friedrich Wessels und Heinrich Clairmont, Hamburg, Felix Meiner, G. W.: Band 9, 1988. Werke, edición a cargo de Eva Moldenhauer y Karl Markus Michel, basada en la edición de 1832-1845, Frankfurt am Main, Suhrkamp, 1986. Fenomenología del espiritu, traducción de Wenceslao Roces, México, F.C.E., 1973, p. 99. 
momentos contrapuestos que se opera como disolución de la clásica oposición entre finito e infinito.

Hegel dice que el ser para sí (Fürsichsein) en cuanto "infinita referencia a sí", supone el retorno sobre la diferencia que separa lo finito de lo infinito: el retorno es la reflexión que asume la diferencia, mostrando que no hay un infinito opuesto a lo finito, como una cosa se opone a otra cosa. Lo infinito es lo que brota en la cosa en tanto ésta surge; es la diferencia que une y determina, la totalidad absoluta, la unitaria condición de posibilidad de todo movimiento. Dice: "No es que la infinitud consista, pues, en la supresión de la finitud en general, sino que lo finito es sólo esto: por su propia naturaleza, llegar a ser infinitud. La infinitud es su determinación, o sea aquello que él es en sî́" (SL, 79; 262).

De este modo, Hegel muestra en la Doctrina del ser de la Ciencia de la lógica, que la noción de ser finito impulsa necesariamente más allá de sí misma hacia una noción de ser infinito que se constituye en su verdad; ésta aparece primeramente en una forma que es inadecuada (el "infinito malo") y se desarrolla en dirección de una forma verdadera. ${ }^{21}$ En este contexto, la categoría de infinito surge como negación de lo finito, es la noción del ser indeterminado que se ha realizado a sí mismo en contraste con la limitación. El movimiento de salir de sí hacia otro, el movimiento de traspasar (binausgehen) es la esencia misma de la finitud. Sólo este movimiento de ir más allá trascendiendo sus límites e incluir en el momento presente los momentos venideros es lo que lleva a lo finito a que, según su concepto, llegue a un final. Lo finito se completa cuando llega a su fin. La identidad resultante es identidad de sí y de lo radicalmente diferente: es para sí. El ser para sí es la superación de la incompletud, de la falta (Fehlers) del ser que está siendo (Dasein) dado que representa el haber regresado a sí superando las diferencias al modo de un infinito referido a sí. Esta providencia le permite a Hegel trazar un paralelo con la filosofía de Leibniz, dado que: “(...) el absoluto en general es algo ideal en cuanto infinita referencia a sí mismo, en cuanto unidad consigo que no está perdido dentro de la exterioridad y del ser otro. La esencia leibniziana representadora, la mónada es esencialmente algo ideal" (SL, 89; 271).

${ }^{21}$ Cfr. Horn, J. C., Monade und Begriff. Der Weg von Leibniz zu Hegel, Wien, Oldenbourg, 1965. 
Leibniz pone la esencia de la sustancia en la fuerza representadora. La naturaleza de la fuerza es su capacidad de representación (vorstellende Kraft). Despliegue de un movimiento interior que no hace sino producir la aparición de lo que es en tanto que aparece y aparece en tanto que es, integrándolo en un juego tan dinámico como creador. Cada mónada lo contiene todo en un sentido infinito (substantia infinitas actiones simul excercet) constituyéndose en una inteligencia para la cual cada representación oscura se transforma en clara y distinta, en la que todas las cosas del mundo, todo lo que es, lo que fue y lo que será, se puede ver representado. El escenario abierto es, por ende, la plenitud desplegada de lo múltiple en la unidad: concordancia de lo diverso en la multiplicidad de los grados de claridad de las diferentes perspectivas.

\subsection{Nada es sin razón de ser}

Leibniz muestra que el paso dado hacia el mundo verdadero accesible a la capacidad representadora y reflexiva de la mónada no alcanza la verdad completa. Al reconocer los límites de su conocimiento, la mónada toma conciencia de su finitud. Descubre que un tal saber no es todo el saber y que el mundo por ella concebido no es el mundo visto desde una perspectiva absoluta sino desde sus posibilidades.

Más aún, la mónada no se puede fundamentar a partir de sí misma y no puede realizarse a través de sí misma, con lo cual, tiene que dejar mediar su automediación por algo precedente a ella. El problema es, pues, el principio de razón suficiente y la posibilidad intrínseca de la idea de Dios. El paso fundamental se cifra en la tesis según la cual la idea del ente perfectísimo no encierra contradicciones, lo que, a su vez, permite otorgar al argumento la forma de una tesis ontológica general: las cosas son porque Dios existe. Dice Leibniz: “(...) y así la razón última de las cosas debe estar en una sustancia necesaria, en la cual el detalle de los cambios no esté sino eminentemente, como en su origen: y esto es lo que llamamos Dios" (Mon., \38).

En esta línea, Leibniz plantea una cuestión límite de la metafísica que la desborda hasta convertirse en uno de los problemas centrales de la filosofía: ¿Es posible Dios? ¿Es posible pensarlo? ¿Es posible que exista? Según él, Dios es posible pues su concepto no es contradictorio: tanto si se lo considera ente perfectísimo cuanto si se lo tiene por ente necesario, su concepto no encierra contradicción, por lo que es posible pensarlo; además, es posible que exista 
porque su esencia no le veda la existencia: antes bien, la requiere. Por lo tanto, si el concepto de Dios es posible, su existencia es demostrable a priori.

Leibniz dice: "no hay más que un Dios y este Dios basta" (Mon., \ 39). No sólo ha de ser posible sino también necesario, no sólo en sí mismo sino para lo creado en cuanto tal. El problema para la razón pensante se cierra sobre lo que sigue: encontrar el punto en el que lo apodíctico y lo problemático puedan traspasarse a lo asertórico. El problema de la metafísica no es la libertad ni la necesidad ni la posibilidad de Dios sino su realidad. En el concepto de la omnitudo realitatis ha de ser pensada la determinación de la existencia. Pero si la existencia no es una realidad (Realität), de la idea de toda realidad no se sigue su existencia objetiva. La respuesta a este problema se torna perentoria para la lógica de la existencia una del sum en sus dos extremos: Dios y el mundo. En efecto, hay una perfección tal que su presencia los consuma y su ausencia los frustra. Esta es la existencia que se eleva como necesaria a la vez que "razón suficiente" de todo lo creado. Dice Hegel:

El principio de razón [o principio de fundamento] dice: Todo tiene su razón [o fundamento] suficiente, esto es, la verdadera esencialidad del algo no es su determinación como idéntico consigo, ni como distinto, ni como meramente positivo o meramente negativo, sino que su verdadera esencialidad es que tiene su ser en otro que, en tanto su idéntico-consigo, es su esencia (...) fundamento lo es solamente en tanto es fundamento de algo, de otro. ${ }^{22}$

Ser necesario significa no poder no serlo. El ser necesario tiene en sí la razón de su propia existencia y es la razón de la existencia de un mundo real que ha sido elegido por él como el mejor entre los muchos posibles. Por la voluntad de Dios, las mónadas alcanzan realidad efectiva (Wirklichkeit). Pero no es la perfección de la mónada individual sino la del sistema la que fue decidida en su admisión a la existencia. El "mejor de los mundos" fue reconocido por la sabiduría, elegido por su bondad y realizado por su poder.

${ }^{22}$ Hegel, G.W.F, Ensyklopädie der pbilosophischen Wissenschaften im Grundrisse (1830), Hrg. Wolfgang Bonsiepen y Hans Christian-Lucas, Hamburg, Felix Meiner. G.W., Band 20, 1991. Enciclopedia de las ciencias filosóficas en compendio, traducción de Ramón Valls Plana, Madrid, Alianza, 1999, \ 121 nota. 
Hegel dice: "Sólo en sí, o sea dentro de Dios como mónada de las mónadas, o también dentro del sistema, son las mónadas algo representador "(SL 89; 272).

Dios no está fuera de su idea, esencia, forma o causa. Sin embargo, el estar dentro de Dios de las mónadas, no debe interpretarse, según Hegel, en el sentido de que Dios sea el mundo. La necesidad óntica de que Dios es[tá] en su creación limita los alcances de la concepción para la cual la persistencia de lo finito frente a lo infinito se da en el sentido de una oposición excluyente e indiferente. Es en la realidad efectiva del mundo donde Dios se expone. La existencia de verdad es la presencia de Dios en y como mundo. Pero estar dentro de Dios implica distinguirse absolutamente de él en tanto es fundamento, lo cual confirma la semejanza y la desemejanza entre ambos. El mundo es algo absolutamente distinto del acto de distinguirse absolutamente del mundo, y este "acto" es el propio de Dios. De allí que, "el dentro de Dios o dentro del sistema" no remitan a una relación estática sino dinámica, más bien, orgánica: la del alma del mundo en el cuerpo del mundo.

Leibniz se distingue tanto del panteísmo como del dualismo. La identificación de Dios con el mundo no salvaría su diferencia ni la de sus criaturas, las cuales disolverían sus atributos de autonomía y espontaneidad en el concepto abstracto de una realidad pura y atemporal. Pero, a su vez, una trascendencia absoluta de Dios frente al mundo podría librarlo de la finitud positivamente constante que caracteriza a la creación, para condenarlo a una exterioridad vacía e inoperante que no se correspondería con el carácter "creador" que le es propio: la necesidad de sí mismo es una necesidad activamente ejercida. En este sentido, Leibniz representa un quebrantamiento reflexivo de aquella forma de exposición de lo absoluto asociada a un "más allá" del mundo entendido como "lo otro" de Dios. Según Hegel, habría aquí una cosmovisión intelectualista del universo ${ }^{23}$ que recupera un sentido de la racionalidad no subordinada a los parámetros de un entendimiento orientado a la negación de lo finito frente a lo infinito absolutizado. Dado que lo que la caracteriza es su "voluntad de verdad", la experiencia del representar se

${ }^{23}$ Ver Hegel, G.W.F., Werke (Theorie Werkausgabe) a cargo de Eva Mondelhauer y KarlMarkus Michel, Frankfurt a. M., Suhrkamp, Vorlesungen über die Geschichte der Philosophie (I/III): Lecciones sobre la historia de la filosofía, III. Traducción española de Wenceslao Roces, México, F.C.E., 1955, p. 343. 
consuma en un proceso de formación, en el constante llegar-a-ser-otro del devenir consciente. Constancia ya no es, entonces, el verificar mecánico de las similitudes sino la captación de la trama de relaciones de la totalidad dinámica de las figuras del mundo. Una "simpatía" que juega en estado libre -porque necesario - del apetito, suscitando el movimiento de las cosas, provocando los acercamientos más distantes y respondiendo al atractivo de un fin. Dice Hegel:

Leibniz estableció ante todo el carácter suficiente del fundamento en contraposición a la causalidad, en su sentido estricto de acción mecánica. Esta referencia, el todo como unidad esencial, se halla sólo en el concepto, en el fin (...) Leibniz, pues, ha entendido por razón suficiente algo que comprendería dentro de sí, no meras causas, sino las causas finales (WL, 293; 499)

\section{Conclusión}

La crítica kantiana es reveladora de la estructura profunda del moderno edificio especulativo de la metafísica. En efecto, por una parte, la razón sólo puede ser si se realiza el ascenso a sus principios, en los que cifra la verdad; por otra parte, sin embargo, confiere carácter de juez de sus verdades a aquello que la niega: la intuición sensible. El concepto de autorreflexión cobra la primacía y la relación del sujeto representador consigo mismo se convierte en el único fundamento de cualquier certeza última. A su vez, el final de la metafísica es la condición de la posibilidad de la episteme moderna, caracterizada desde el principio por la aporía consistente en que el sujeto cognoscente se levanta por encima de las ruinas de la "dogmática" para, con la conciencia de la finitud de sus fuerzas, resolver una tarea que requiere una fuerza infinita. En este contexto, el "dogmatismo" es visto por Kant como exceso, esto es, como el paso subrepticio de lo teóricamente válido a las ideas de Dios, de Alma y de Mundo. En este sentido, lo que Kant ataca en la refutación al "dogmatismo" de Leibniz es la autonomía del ámbito interno de la subjetividad cognoscente, en una configuración puramente "mental", cuando, en realidad, la unidad sintéticotranscendental de la conciencia debe considerarse la condición de todo conocimiento que se precie de objetivo, pero siempre en relación con la sensibilidad -último reducto de lo ininteligible. 
Para Hegel, Leibniz conserva su ejemplaridad. Dado que la crítica kantiana era, por su parte, una crítica a "la intelectualidad de los fenómenos" operada por Leibniz ( $K r V$ A 271, B 327), la crítica a la crítica viene a significar ahora una cierta rehabilitación del filósofo de Leipzig. En diversos momentos del despliegue de "lo lógico" en la Ciencia de la lógica, la "monadología" encontrará una nueva distancia interrogativa y expansiva para el desarrollo y alcance de sus principios.

Según Hegel, la filosofía de Leibniz representa un cambio de signo de la posibilidad intrínseca de la metafísica y del sentido último de la racionalidad de lo real en su estructura y dinamismo. Si toda mónada es solamente en su límite, pero, además, en el rebasamiento de sus propias limitaciones en pos de un fin que la impulsa más allá de sí, entonces toda su finitud es esencialmente ideal, puesto que su realidad está en su propia negación. Su identidad, ser simple negatividad refiriéndose a sí (Für sich), no es un problema de la reflexión exterior, sino que se ha dado como resultado de su propia apetencia: "Una predestinación puesta por un ser distinto de ella" (WL, 378; 601). Su autorreferencia pone así de manifiesto una objetividad otra a la cual la mónada está predestinada, tanto por la certeza de sus condiciones de existencia como por la idea de la posibilidad de una individualidad que sólo se hace efectiva en el marco de un sistema en el que todo es diverso. Dios es la diferencia intensiva de la primacía de la esencia sobre la existencia, umbral iniciático, exterioridad absoluta en tanto y en cuanto en Él se reconoce un origen del cual se procede de una vez y para siempre. Pero, al mismo tiempo, interioridad y presencia de lo divino en la intimidad de la sustancia, que tanto inhabilita toda distancia objetivante como hace posible la experiencia de "ser-todo" en la más profunda precariedad y contingencia del no-ser de todo lo creado: la verdadera infinitud de lo finito.

Para Hegel, el diálogo con la historia de la filosofía tiene un carácter de superación, esto es, de comprensión mediadora al modo de la absoluta fundamentación. Su sistema es, en un sentido, la contrarréplica del pensamiento de Leibniz, aunque en este punto no pueden dejar de reconocerse sus convicciones compartidas. Se puede mostrar hasta qué punto el concepto mismo de sujeto en Hegel resulta aporético, sin embargo, no se ve cómo pueda seguir siendo comprensible aquella fórmula del Prefacio a la Fenomenología del espiritu que reza: “(...) todo depende de que lo verdadero no se aprehenda y se 
exprese como sustancia, sino también y en la misma medida como sujeto" (Phä., 15) cuando se pasa por alto su relación con el pensamiento de Leibniz.

\section{Bibliografía}

Belaval, I., "La doctrine de l'essence chez Hegel et chez Leibniz", Études leibniziennes. De Leibniz à Hegel, Paris, Gallimard, 1976, pp. 264-378.

Bristow, W. F., Hegel and the Transformation of Philosophical Critique, Oxford, Clarendon Press, 2007.

Bruaire, C., "Leibniz et la critique hegelienne", Studia Leibnitiana, Suppl. V: Akten der Internationalen Leibniz-Kongresses, Hannover, 1966, Bd. V, pp. 116-123.

Caimi, M., Beade, I., Gónzalez Ríos, J., Marey, M., Moledo, F., Paolucci, M., Pringe, H. y Thisted, M., Diccionario de la filosofía crítica kantiana, Buenos Aires, Colihue, 2017.

Di Sanza, S. y López, D. M. (comps.), El vuelo del búbo. Estudios sobre filosofía del idealismo, Buenos Aires, Prometeo, 2013.

Düsing, Klaus, "¿Cogito, ergo sum? Untersuchungen zu Descartes und Kant" en Wiener Jahrbuch für Philosophie, XIX, 1987.

Falckenberg, Richard, Geschichte der neueren Philosophie, Leipzig, Verlag von Veit \& Comp. 1908.

Fernández, J. E., Finitud y mediación. La cualidad en la Lógica de Hegel, Buenos Aires, Ediciones del signo, 2003.

Goddard, J.-Ch. (ed.), Le transcendental et le spéculatif dans l'idéalisme allemand, París, Vrin, 1999.

Guyer, P., "Hegel, Leibniz und der Widerspruch im Endlichen", in Seminar: Dialektik in der Philosophie Hegels, Hrg. von R. P. Horstmann, Frankfurt a M., Shurkamp, 1989, pp. 230-260.

Harnischmacher, I., Der metaphysische Gebalt der Hegelschen Logik. Stuttgart-Bad Cannstatt, Frommann-Holzboog, 2001. 
Hegel, G.W.F., Wissenschaft der Logik. Erster Band. Die objektive Logik (18121813). Hrg. von Fr. Hogemann/Walter Jaeschke. Meiner. Hamburgo (Düseldorf) 1978. En: (Gesammelte Werke, Hrg. von der RheinischWestfälischen Akademie der Wissenschaften. Bd. 11). Traducción de Félix Duque, Madrid, Abada Editores, 2011. Die Lehre vom Sein (1832) H.-J. GawollW. Jaeschke, Hamburg, Felix Meiner Verlag, 2008. Traducción de Rodolfo Mondolfo, Buenos Aires, Solar, 1968.

Hegel, G.W.F., Phänomenologie des Geistes, Hrg. Hans-Friedrich Wessels und Heinrich Clairmont, Hamburg, Felix Meiner, G. W.: Band 9, 1988. Werke, edición a cargo de Eva Moldenhauer y Karl Markus Michel, basada en la edición de 1832-1845, Frankfurt am Main, Suhrkamp. Fenomenología del espiritu, Traducción española de Wenceslao Roces. F.C.E., 2da. Reimpresión, México, 1973.

Hegel, G.W.F, Enzyklopädie der pbilosophischen Wissenschaften im Grundrisse (1830), Hrg. Wolfgang Bonsiepen und Hans Christian-Lucas, Hamburg, Felix Meiner. GW: Band 20, 1991. Enciclopedia de las ciencias filosóficas en compendio, traducción de Ramón Valls Plana, Madrid, Alianza, 1999.

Hegel, G.W.F., Werke (Theorie Werkausgabe) a cargo de Eva Mondelhauer y KarlMarkus Michel) Frankfurt a. M., Suhrkamp, Vorlesungen über die Geschichte der Philosophie (I/III): Lecciones sobre la historia de la filosofía, III. Traducción española de Wenceslao Roces, México, F.C.E., 1955.

Horn, J. C., Monade und Begriff. Der Weg von Leibniz, zu Hegel. Wien, Oldenbourg, 1965.

Kant, I. Prolegomena zu einer jeden künftigen Metaphysik, die als Wissenschaft wird auftreten Können: Prolegómenos a toma metafísica futura que haya de poder presentarse como ciencia, traducción de Mario Caimi, edición blingüe, Madrid, Ágora de Ideas/Istmo, 1999.

Kant, I., Por qué no es inútil una nueva crítica de la razón pura. Respuesta a Eberhard, traducción de A. Castaño Piñán, Buenos Aires, Aguilar, 1963.

Kant, I., Los progresos de la metafísica desde Leibnizy Wolff, traducción de Félix Duque, Madrid, Tecnos, 2002. 
Kant, I., Kritik der reinen Vernunf, Kant's gesammelte Schriften. Hrsg. von der Königlich Preussichen Akademie der Wissenschaften, Berlin und Leipzig, Walter der Gruyter, desde 1902. Crítica de la razón pura, traducción de Mario Caimi, Buenos Aires, Colihue, 2007.

Leibniz, G. W.: "Aus dem Briefwechsel zwischen Leibniz und Arnauld", in Hauptschr iften zur Grundlegung der Philosophie, Bd. 2, hg.v. A. Buchenau, Hamburg, Meiner, 1966.

Leibniz, G. W., Die philosophischen Schriften, Bde. I-VII, hrsg. von C. J. Gerhardt (unveränderter Nachdruck der Ausgabe von 1875-1890), Hildesheim, Georg Olms, 1965.

Leibniz, G. W., Monadología, traducción española de Julián Velarde, edición trilingüe, Oviedo, Pentalfa, 1981.

Leibniz, G. W., Discurso de Metafísica, traducción de A. Castaño Piñán, Buenos Aires, Aguilar, 1984.

Leibniz, G.W., Nuevos ensayos sobre el entendimiento bumano, traducción de J. Echeverría, Madrid, Editora Nacional, 1983.

Lerussi, N. y Solé, María Jimena (eds.), En busca del idealismo. Las transformaciones de un concepto, Buenos Aires, RAJGIF Ediciones, 2016.

Longuenesse, B., Hegel's Critique of Metaphysics, Nueva York, Cambridge University Press, 2009.

López, D. M. y Gaudio, M. (comps.), Variaciones sobre temas del idealismo, Buenos Aires, RAJGIF, 2018.

Lucas, H.-C., "Das Eine und/als das Andere. Zur systematischen Bedeutung von Hegels Leibniz- Rezeption", Leibniz. Werk und Wirkung, IV Internationaler Leibniz-Kongress (Vorträge), hrsg. von der G.W.-Leibniz-Gesellschaft, 1983, pp. 433-441.

Lütterfelds, W., "Kant's 'Ich denke...' als grammatischer Satz" en: Kant und die Berliner Aufklärung. Akten des IX. Internationalen Kant-Kongresses, Berlin, Walter de Gruyter, t. 2, 2001.

Manninen, J., "Die Leibnizsche Monadologie In Hegels Wissenschaft der Logik", Leibniz, Tradition und Aktualität, Hannover, 1988, pp. 519-524. 
Poser, H., "Monade, Monas; II. Von Leibniz bis Kant", in Historisches Wörterbuch der Philosophie, hrg. von J. Ritter und K. Gründer, Bd. 6, Basel, Scheidegger und Spiess, 1984, pp. 117-121.

Schmidinger, H., Metaphysik, Stuttgart, Verlag W. Kohlhammer, 2006.

Zingari, G., Leibniz, Hegel e l'Idealismo Tedesco, Milano, Mursia, 1991.

Zocher, R.: "Kants transzendentale Deduktion der Kategorien", Zeitschrift für philosophische Forschung, 8, 1954. 